\title{
Kolonoskopi ile saptanan intestinal endometriozis: Nadir bir olgu sunumu
}

\author{
Intestinal endometriosis identified by colonoscopy: A rare case report
}

\author{
Bilge BAŞ¹ , Bülent DINÇ², Nazif Hikmet AKSOY ${ }^{3}$, Ayhan Hilmi ÇEKIN ${ }^{1}$ \\ Sağlık Bilimleri Üniversitesi Antalya Eğitim ve Araştırma Hastanesi, ${ }^{1}$ Gastroenteroloji Bölümü, Antalya \\ Atatürk Devlet Hastanesi, ${ }^{2}$ Genel Cerrahi Bölümü, ${ }^{3}$ Patoloji Bölümü, Antalya
}

\begin{abstract}
Endometriozis fonksiyonel endometrial stroma ve glandlarin uterus kavitesi dışında yerleşmesidir. Ektopik endometrium dokusu çoğunlukla pelvik organlar, overler, pelvik periton, rektovajinal septum ve servikse yayllir. Bunlar arasında intestinal endometriozis nadir görülen önemli bir durumdur. Intestinal endometriosiz en sık rektosigmoid ve rektovajinal septumda görülür Periyodik rektal kanama, pelvik ağrı en belirgin semptomlarıdır. Bu vaka sunumunda, pelvik ağrı ve rektal kanama şikayeti olan ve intestinal endometriozis tanısı koyulan hasta sunulmuștur.
\end{abstract}

Anahtar kelimeler: Endometriozis, rektal kanama, pelvik ağrn, kolonoskopi

\section{GİRIS}

Endometriozis, fonksiyonel endometrium dokusunun uterin kavite dışındaki alanlarda ektopik olarak bulunmasıyla oluşan benign bir hastalıktır. Genellikle üreme çağındaki kadınlarda görülür (1). Uterus kasları icinde yerleşen endometrial dokuya internal endometriozis, diğer alanlarda görülenlere ise eksternal endometriozis denir (2). Endometriozis en sik pelvik boşlukta görülmekle beraber, ekstrapelvik endometriozis şeklinde vücudun her organında görülebilir. Ektopik endometrium dokusunun sıklıkla görüldüğü pelvik organlar; overler, pelvik periton, rektovajinal septum, Douglas boşluğu ve servikstir. Pelvik organlar dışında vücutta akciğerler, plevra, diyafragma, barsaklar, safra kesesi, böbrekler, üreterler, umblikus, cilt, santral sinir sistemi ve ekstremiteler gibi hemen her organda görülebilir (3). Intestinal tutulum özellikle rektosigmoid bölgededir. Pelvik endometrioziste hastalar, menstruasyonun periyodunun 3-4 gün öncesinden başlayıp kanamanın ilk birkaç gününe kadar devam eden siklik ağrlardan şikayet ederken intestinal endometrioziste farklı şiddetlerde periyodik rektal kanama, pelvik ağrı, karın ağrısı, konstipasyon ya da tekrarlayan diyare, şişkinlik, gaz en belirgin semptomlardır. Bu şikayetlerin yanı sıra ileus ve akut batın gibi acil klinik durumlara da yol açabilirler. Bu nedenle intestinal endometriozis; Crohn hastalığı, apandisit,
Endometriosis, functional endometrial stroma, and glands is a settlement outside the uterine cavity. Ectopic endometrial tissue spreads mostly to the pelvic organs, ovaries, pelvic peritoneum, rectovaginal septum, and cervix. Among these, intestinal endometriosis is an important and rarely encountered condition. Intestinal endometriosis is most commonly seen in the rectosigmoid and rectovaginal septum. Periodic rectal bleeding and pelvic pain are the most common symptoms. In this case report, we present a patient who was admitted with complaints of pelvic pain and rectal bleeding and was diagnosed with intestinal endometriosis.

Key words: Endometriosis, rectal bleeding, pelvic pain, colonoscopy iskemik kolit, divertikülit, soliter rektal ülser ve maligniteler ile karıştırılabilir, bu da teşhisin geç konulmasına neden olabilir (4). Bu nedenle tanı ve tedavide gastroenterologların, jinekologların, cerrahların ve patologların ortak çalışmaları gerekmektedir.

Burada pelvik ağrı ve rektal kanama nedeni ile başvuran ve intestinal endometriyozis teşhisi konulan hasta sunulmaktadır.

\section{OLGU SUNUMU}

Kırküç yaşında, kadın hasta yaklaşık son 5 yıldır ara ara olan müphem karın ağrısı ve son 3 aydır olan rektal kanama şikayetleri ile cerrahi polikliniğine başvurdu. Anamnezde kanamanın spesifik olarak menstruasyonla ilişkisinden bahsetmiyordu. Son zamanlarda karın ağrısının daha belirgin olduğu ve batın alt kadranda, özellikle sağ bölgeye lokalize olduğunu belirtiyordu. Hastanın normal doğum ile dünyaya gelmiş, sağlıklı iki çocuğu vardı ve hiç düşük anemnezi yoktu. Yirmi sekiz-otuz günde bir olan ve ortalama beş gün süren düzenli menstruasyon tarifliyordu. Herhangi bir sistemik hastalığı ve düzenli kullandığı ilaç bulunmuyordu. Fizik muayene bulguları normal saptandı. Rektal tuşede ele bulaşan kan ya da başka bir özellik yoktu.
İletişim: Bilge BAŞ Sağlık Bilimleri Üniversitesi Antalya Eğitim ve Araştırma Hastanesi, Gastroenteroloji Bölümü, Antalya E-mail: bilgeormeci@hotmail.com Geliş Tarihi: 18.01.2018 Kabul Tarihi: 12.02.2018 
Yapılan batın ultrasonografisi normal olarak değerlendirildi. Başvuru hemoglobin 11.2 gr/dl idi. Biyokimyasal tetkiklerde özellik saptanmadı. Rektal kanama etiyolojisini araştırmak amaciyla hastaya kolonoskopi yapildı. Kolonoskopide anal kanaldan itibaren 15. cm'de endoskopun geçişine izin vermeyen, lümeni çepeçevre saran, vejetan kitle izlendi (Resim 1), Kitleden multipl biyopsiler alındı. Patoloji ile spesifik bir tanı konulamadığından kolonoskopik biyopsi işlemi üç kez tekrarlandı. Tekrarlayan biyopsiler ile tanı konulamaması, kitlenin lümeni tama yakın obstrükte etmesi ve kolonoskopik görünümün malignite düşündürtmesi nedeniyle hastaya cerrahi operasyon önerildi. Hastaya low anterior rezeksiyon prosedürü uygulandı. Cerrahi materyalinin histopatolojik incelemesinde rektum duvarının tüm katlanı ve perirektal yağ dokusuna infiltre Sitokeratin7 (CK7), Sitokeratin10 (CK10), Sitokeratin20 (CK20), CDX2 ve östrojen reseptör (ER) paneli ile pozitif boyanan endometriozis odakları görülmüştür (Resim 2).

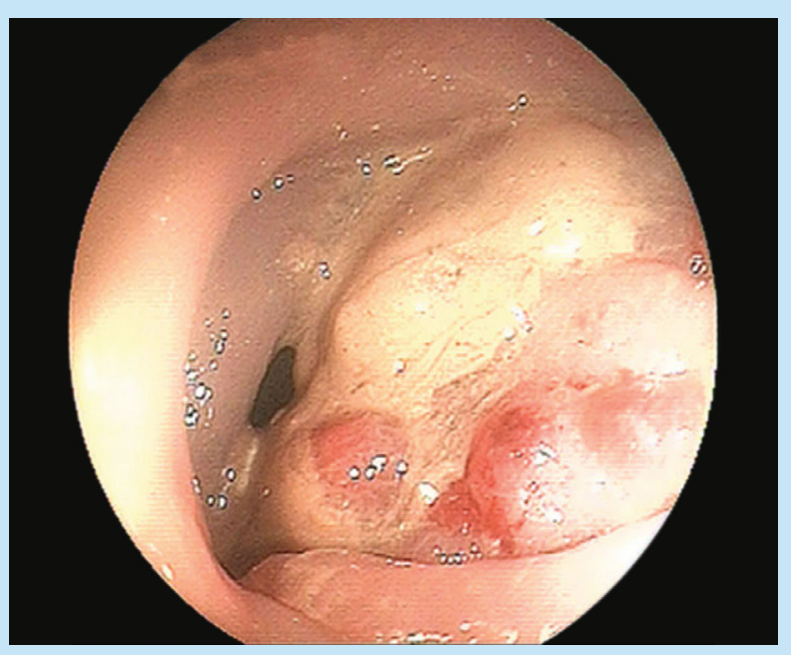

Resim 1. Lümeni tıkayan kitlenin kolonoskopi görüntüsü.

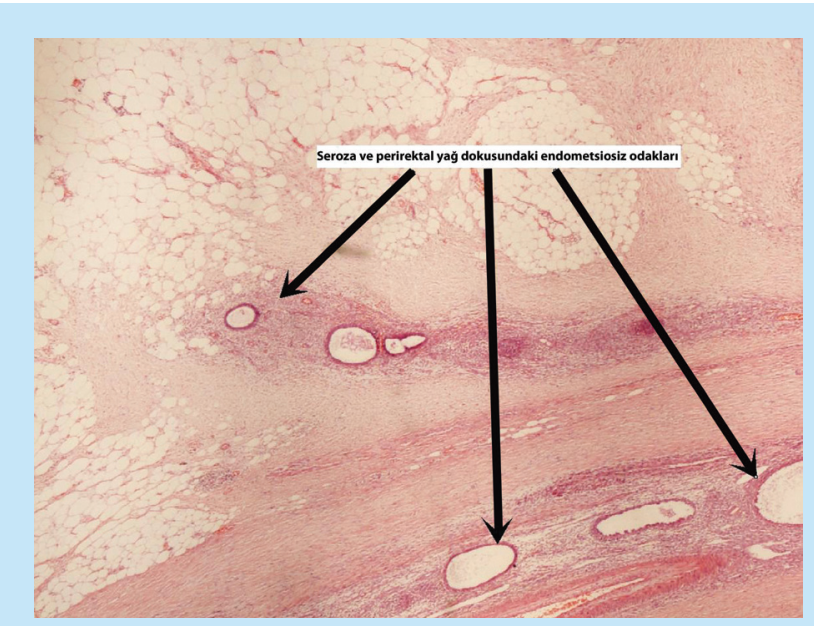

Resim 2. Seroza ve perirektal dokudaki endometriosiz implantları (Hemotoksilen Eosinx2).

\section{TARTIŞMA}

Fonksiyonel endometriyal gland ve stromanin uterin kavite dışında bulunması olarak kabul edilen endometriozisin reprodüktif dönemdeki kadınlardaki prevalansı \%8-15 arasinda değişmektedir (5). Endometriozis vücudun değişik bölgelerinde yerleşebilmektedir. Pelvik yerleşim en sık overlerde (\%54.9), posterior broad ligamentde (\%35.2), anterior culde-sac'da (\%34.6), posterior cul-de-sac'da (\%34) ve uterosakral ligamentde (\%28) olmaktadır (1). Pelvis dışı yerleşim en sık bağırsak, deri ve akciğerde gözlemlenir. Intestinal endometriozisin en sik yerleşim yerleri ise rektosigmoid (\% 74) ve rektovajinal septumdur (\% 12), daha az olarak ince barsaklar, çekum (\%2) ve appendiksde (\%3) olabilir (4).

Endometriozisin patogenezinde değişik teoriler ortaya atılmıştır. Metaplazi teorisi, vasküler yayılım, retrograd menst-

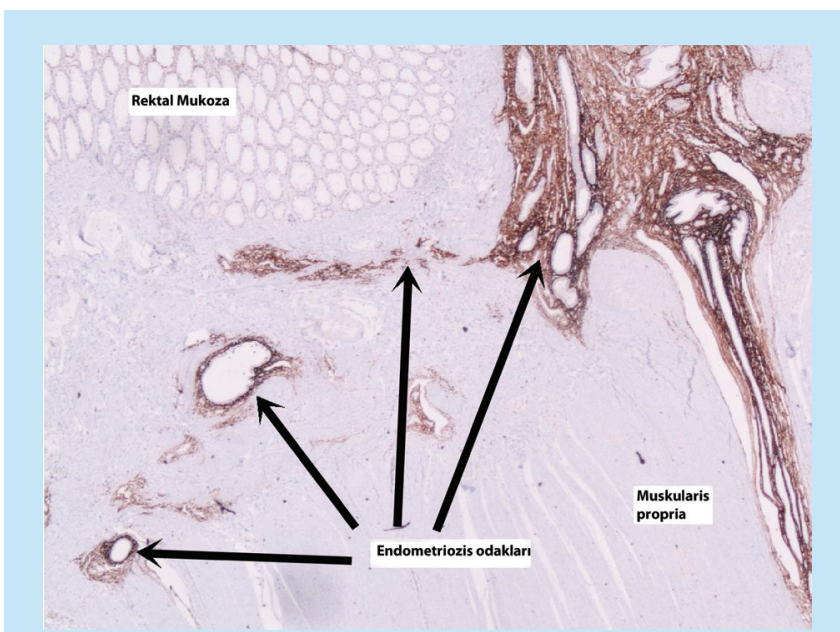

Resim 3. Rektum duvarında görülen endometrial bezler ve stromalar. Endometrial stroma pozitif CD10, x2.

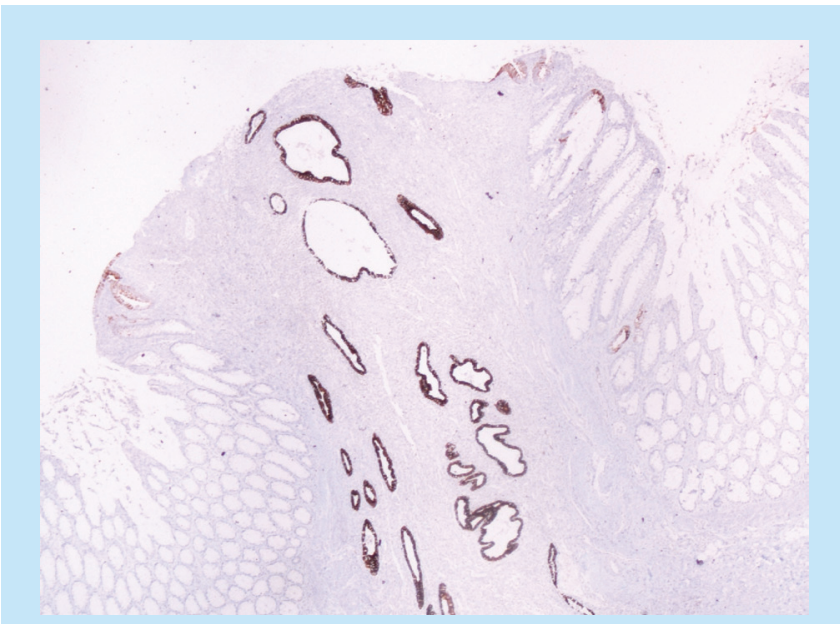

Resim 4. Lamina propria ve submukozada endometriosiz infiltrasyonu olan rektum mukozası. Kolon epiteli negatif kontraslı, endometrial bezler pozitif $\mathrm{CK} 7, \mathrm{X} 2$. 
ruasyon gibi pek çok teori mevcut olsa da günümüzde en fazla kabul göreni menstruasyon sırasında hala can $\neg$ lı olan endometrial hücrelerin taşınmasına dayanan transplantasyon teorisidir (6). Ancak bu teorilerin hiçbiri beyin, akciğer gibi uzak organlardaki endometriozisi açıklamaz (1).

Endometriozis tanısı alan olguların üçte biri asemptomatiktir. Klinik bulguların şiddeti de hastaya göre değişir. En sık karşılaşlan şikayetler pelvik ağrı, sekonder dismenore, disparoni, adet düzensizliği ve infertilitedir (5). Intestinal endometriozisli hastalar asemptomatik olabilecekleri gibi, hastalarda rektal kanama, şiddetli pelvik ağrı, karın ağrısı, konstipasyon, diyare ve gaz şikayetleri olabilir. Bunlar arasında rektal kanama en önemli semptom olmaktadır (4). Vakamızın da karın ağr1s1, rektal kanama, kabızlık şikayetleri mevcuttu. Ancak hastanın rektal kanamasının menstruel sikluslar ile ilişkisi yoktu.

Intestinal endometriozisli hastalarda tablo Crohn hastalığı, appendisit, iskemik kolit, divertikülit, malignite ve soliter rektal ülseri ile karışabileceğinden tanı sıklıkla zor ve geç konulabilmektedir (4). Bizim hastamızda kolonoskopide endoskopun geçişine izin vermeyen obstrüksiyon ve endometriozis dokusunun vejetan görünümde olması öncelikle malignite düşündürmüş olup tanıyı kesinleştirmek için kolonoskopi ile multiple biyopsiler alınmıştır. Üç kez tekrarlanan patolojik inceleme sonrasında tam bir tanı konulamaması ve obstrüksiyonun olması nedeniyle tekrar kolonoskopi planlanmadan cerrahi yapılmıştır.

\section{KAYNAKLAR}

1. Solmaz Ö, Bozan M, Kanat B. Endometriozise bağlı akut apandisit: Olgu sunumu. Kolon Rektum Hast Derg 2013;23:147-9.

2. Simoglou C, Zarogoulidis P, Machairiotis N, et al. Abdomi $\neg$ nal wall endometrioma mimicking an incarcerated hernia: a case report. Int J General Med 2012;5:569-71.

3. Singh A. Umbilical endometriosis mimicking as papilloma to general surgeons: A case report. Australas Med J 2012;5:272-4

4. Kılıç ZMY, Özin Y, Kaçar Z, et al. Intestinal endometriozis: Nadir bir olgu sunumu. Akademik Gastroenteroloji Dergisi 2008;7:114-7.
Ülser ve inflamasyonun belirgin olduğu olgularda lezyon histopatolojik incelemede soliter rektal ülser ya da inflamatuvar barsak hastalığı ile karışabilir. Mukozanın normal morfolojide olduğu tubal metaplazi gelişen olgularda siliaların görülmesi endometrial glandların ayırt edilmesinde yararlı olabilir. CK7, CK20, CDX2 ve ER paneli uygulanması şüpheli olgularda endometriozis tanısında yararlıdır (7). Bizim vakamızda CK7, CK10, CK20, CDX2 ve ER paneli uygulanmış ve endometriozis ile uyumlu bulunmuştur (Resim 3,4).

Kolonik endometrioziste bizim vakamız gibi lümeni daraltan lezyonun obstrüksiyon yapmasına bağlı perforasyon ve peritonit olabilmektedir. Bu da akut batın ve acil operasyona sebep olabilir. Ince barsak tutulumunda ise Crohn hastalığı kliniğine benzer şekilde daha çok karın ağrısı ve şişkinlik ön planda olmaktadır. Çekumu tutan endometrioziste özellikle menstrual siklus dönemlerinde akut apandisiti taklit eden klinik görülebilir. Appendiks endometriozisi ise nadir olarak appendektomi materyallerinde görülebilmektedir. Intestinal endometriozisin tedavisinde genellikle cerrahi yöntem tercih edilmektedir (6). Hormon supresyon tedavisi genellikle cerrahi yapilamayan hastalarda kullanılsa da yanıtlar genellikle iyi değildir. Hormonal tedavinin ilerleyen endometriozisin oluşturduğu ülser, düz kas hipertrofisi, hemoraji ve inflamasyondan kaynaklanan adezyona bağlı darlık semptomları üzerinde düzeltici etkisi yoktur. Cerrahi yöntem olarak tutulmuş barsak segmentinin rezeksiyonu ve anastomoz tercih edilen yöntemdir.
5. Soylu L, Aydın O, Aydın S, Özçay N. Akut apandisite neden olan endometriozise bağlı appendiks invaginasyonu: Olgu Sunumu. Ulusal Cer Derg 2014;30:106-8.

6. Hasegawa T, Yoshida K, Matsui K. Endometriosis of the appendix resulting in perforated appendicitis. Case Rep Gastroenterol 2007;1:27-31.

7. Jiang W, Roma AA, Lai K, et al. Endometriosis involving the mucosa of the intestinal tract: a clinicopathologic study of 15 cases. Mod Pathol 2013;26:1270-8. 